\title{
Oedema of Acute Onset, A Presentation of Round Worm Intoxication
}

\author{
Dr. Avinash Shankar ${ }^{1 *}$, Dr Amresh Shankar ${ }^{2}$, Dr. Anuradha Shankar ${ }^{3}$ \\ ${ }^{1} M D($ internal Medicine),DNB(E\&M);PhD Postgraduate in Endocrinology \& Metabolism (AIIMS-Delhi) \\ Chairman ,National Institute of Health \& Research Institute of Applied Endocrinology Warisaliganj (Nawada) \\ Bihar 805130, India. \\ ${ }^{2}$ BAMS (BRABU) MHA, Hon Director AarogyamPunarjeevan Ram Bhawan, Ara Garden Road, Jagdeopath, \\ Baily Road PATNA 14,800014, India. \\ ${ }^{3} B A M S$ (BRABU) Senior Research Fellow Regional Institute of Ayurveda, Itanagar (Arunachal Pradesh), India. \\ *Corresponding Author: Dr. Avinash Shankar, MD(internal Medicine),DNB(E\&M);PhD Postgraduate \\ in Endocrinology \& Metabolism (AIIMS-Delhi) Chairman, National Institute of Health \& Research Institute \\ of Applied Endocrinology Warisaliganj (Nawada) Bihar 805130, India.
}

\begin{abstract}
Generalized oedema is a common manifestation of hepatic and renal pathology but uncommon with round worm. Round worm infestation remain a most widely prevalent parasitic infection among the population of tropical and developing countries.
\end{abstract}

Material: 20 cases of acute generalised oedema in patients of age group ---attending at National institute of health \& Research with normal hepato renal, diabetic and haematological profile were assessed.

Methods: All cases were thoroughly interrogated, clinically examined and investigated for bioparameters, all shows raised eosinophil count graded and treated accordingly .

Results: All had complete recovery in 20 days without any adversity, sequel or withdrawal of manifestation in 3 months' post therapy follow up.

Conclusion: In any case of sudden generalised pitting oedema with normal haematological, hepatic, renal and diabetic profile, consider Roundworm as its pathogenic factor ..

Keywords: Oedema, bioparameters, hepto renal

\section{INTRODUCTION}

Round worm is a common infestation among population of tropical and developing countries and presents with varied manifestation though abdominal colic, nausea, vomiting and diarrhoea are common manifestation but presentation like sudden onset of generalised oedema is very uncommon

Angioedema is an anatomically limited non pitting oedema or deep subcutaneous swelling and 50\% children who had urticaria presents with angioedema which is transient extravasation of plasma to the dermis causing a wheal characterised by tense oedema with or without redness. Usually generalised pitting oedema is a result of hepatic, renal or malnutrition origin. Manifestation like diarrhoea, vomiting, intestinal obstruction and perforation, encephalopathy are well documented but acute generalised pitting oedema due to Round worm infestation remain not widely publicized.

\section{Pathology:}

In majority cases mast cells releases histamine rapidly from mediator leukotriene and prostaglandin but in some cases due to ACE inhibitor effect results in release of bradykinin formation, a potent vasodilator result in Oedema

Globally more than 1.5 billion or $24 \%$ world population are infected with

Soil transmitted helminthic infection. In India as per 2015 survey 2.41 million children are affected with Ascaris lumbricoides $\left({ }^{1-10)}\right.$. 


\section{Factors contributing oedema 11:}

- increased hydrostatic pressure;

- reduced colloidal or oncotic pressure within blood vessels;

- increased tissue colloidal or oncotic pressure;

- increased blood vessel wall permeability (e.g., inflammation);

- obstruction of fluid clearance in the lymphatic system;

- changes in the water retaining properties of the tissues themselves. Raised hydrostatic pressure often reflects retention of water and sodium by the kidneys.

\section{Grading of Oedema:}

Clinical Grade
Mild
Moderate
Severe

2. Material \& Methods

\subsection{Material}

20 cases of sudden generalised oedema admitted at Centre for Critical care, National Institute of Health \& Research, Warisaliganj (Nawada) during January 2017 to March 2019 were considered for study and evaluation.

\subsection{Methods}

Selected patients and their parent were thoroughly interrogated for onset and prodrome of clinical presentations, clinically examined, investigated and administered the therapeutic regime. all patients were assessed for base line bio parameters and repeated after completion of treatment to assess the safety profile and consequent effect.

Therapeutic regime administered:

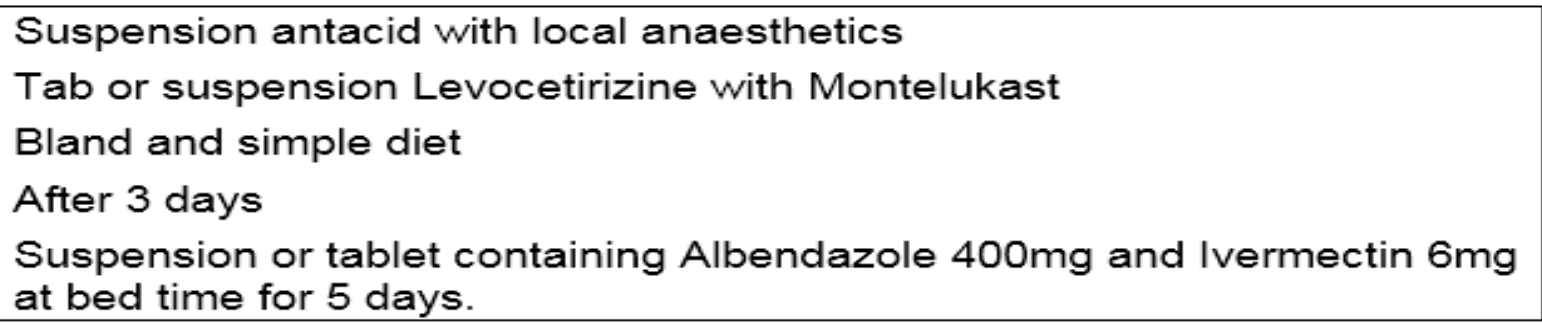

Each patient were advised to note regression of oedema and any consequent sequel during the therapy, in addition during post therapy follow patients and their parent were advised to keep a vigil watch on any evident oedema and continuance oaf deworming every month three days for 6 month.

Table \& Legends:

Table1. Showing distribution of patients as per age \& sex

\begin{tabular}{|lccc|}
\hline Age group & \multicolumn{3}{c|}{ Number of patients } \\
\hline (in years) & Male & Female & Total \\
\hline $10-15$ & 02 & 01 & 03 \\
\hline $15-20$ & 05 & 03 & 08 \\
\hline $20-25$ & 06 & 03 & 09 \\
\hline & 13 & 07 & 20 \\
\hline
\end{tabular}


Male female composition

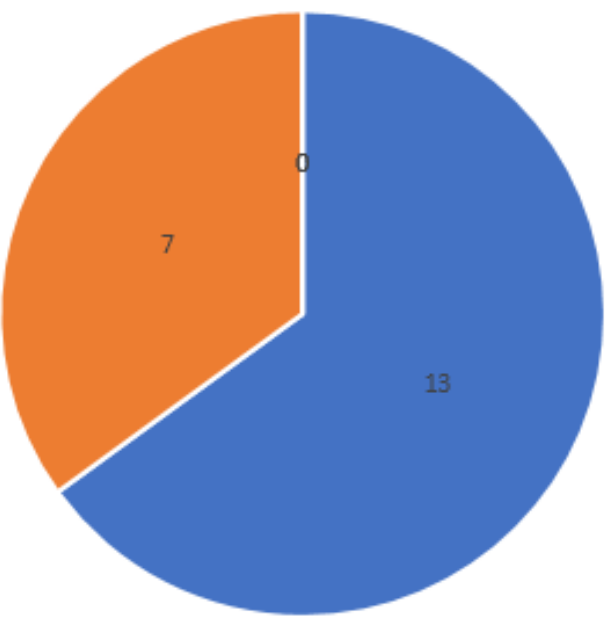

- Male

- Female

Fig1. Pie diagram showing male female composition

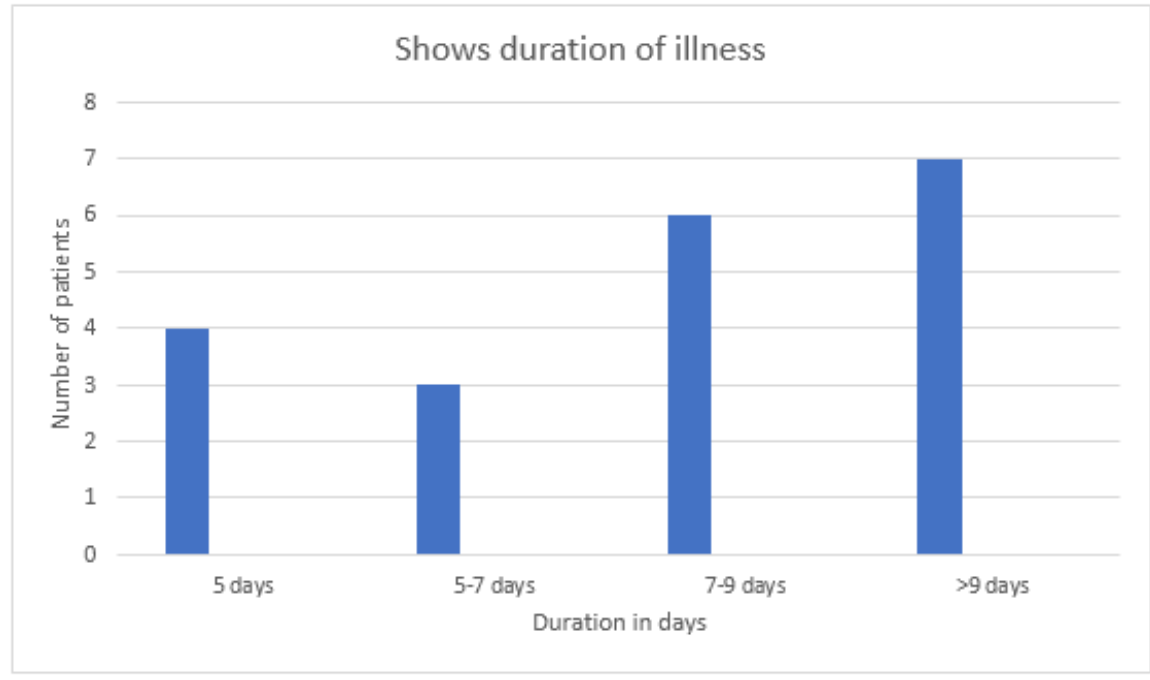

Fig2. Bar diagram showing duration of illness

Table2. Commonest presentations

- Generalised oedema

- Loss of appetite

- General debility

- Giddiness

- Irregular bowel habits

- Pain in abdomen

- Nausea without any vomiting

- Lethargy

Table3. Patients were also interrogated for

- Urinary discomfort if any

- Pain in vertebra costal region (Renal angle tenderness)

- Any agonising itching or urticaria

- Any previous history of such attacks i.e. generalised oedema

Table4. Clinical examination

- All had pitting generalised oedema

- Respiratory system: wheeze present in all cases

- Renal angle tenderness - absent in all

- All had body weight, the ideal body weight as per age and height.

International Journal of Clinical Chemistry and Laboratory Medicine (IJCCLM) 
Table5. Showing basic bio parameters

\begin{tabular}{|c|c|}
\hline Basic bio parameters & Number of Patients \\
\hline \multicolumn{2}{|l|}{ HEMATOLOGICAL } \\
\hline \multicolumn{2}{|c|}{ Absolute eosinophil count } \\
\hline $200-300 /$ & 9 \\
\hline $300-400 /$ & 8 \\
\hline $400-500 /$ & 3 \\
\hline \multicolumn{2}{|l|}{ TLC } \\
\hline 6000-7000/ & 13 \\
\hline$>7000 /$ & 7 \\
\hline \multicolumn{2}{|l|}{ Haemoglobin percent } \\
\hline$<10 \mathrm{gm}$ & 11 \\
\hline$>10 \mathrm{gm}$ & 9 \\
\hline \multicolumn{2}{|l|}{ DIABETIC PROFILE } \\
\hline \multicolumn{2}{|l|}{ Blood sugar } \\
\hline \multicolumn{2}{|l|}{ Fasting : } \\
\hline$<100 \mathrm{mg}$ & 20 \\
\hline$>100 \mathrm{mg}$ & 00 \\
\hline \multicolumn{2}{|l|}{ Post prandial : } \\
\hline$<150 \mathrm{mg}$ & 20 \\
\hline$>150 \mathrm{mg}$ & 00 \\
\hline \multicolumn{2}{|l|}{ HEPATIC PROFILE } \\
\hline \multicolumn{2}{|l|}{ SGOT: } \\
\hline$<30 \mathrm{IU}$ & 20 \\
\hline$>30 \mathrm{IU}$ & 00 \\
\hline \multicolumn{2}{|l|}{ SGPT: } \\
\hline$<30 \mathrm{IU}$ & 20 \\
\hline$>30 \mathrm{IU}$ & 00 \\
\hline \multicolumn{2}{|l|}{ Alakaline phosphatase } \\
\hline$<140 \mathrm{mg}$ & 20 \\
\hline$>140 \mathrm{mg}$ & 00 \\
\hline \multicolumn{2}{|c|}{ RENAL PROFILE } \\
\hline \multicolumn{2}{|l|}{ Blood urea : } \\
\hline$<26 \mathrm{mg}$ & 20 \\
\hline$>26 \mathrm{mg}$ & 00 \\
\hline \multicolumn{2}{|l|}{ Serum creatinine: } \\
\hline$<1.5 \mathrm{mg}$ & 20 \\
\hline$>1.5 \mathrm{mg}$ & 00 \\
\hline \multicolumn{2}{|l|}{ Urine : } \\
\hline \multicolumn{2}{|l|}{ Albumin: } \\
\hline Present & 00 \\
\hline Absent & 20 \\
\hline \multicolumn{2}{|l|}{ RBC: } \\
\hline Present & 00 \\
\hline Absent & 20 \\
\hline
\end{tabular}

Table6. Outcome of therapy

\begin{tabular}{|c|c|}
\hline Particulars & Number of patients \\
\hline Generalised oedema & None \\
\hline Alteration in & None \\
\hline Hepatic profile & None \\
\hline Renal profile & 18 \\
\hline Haematological : & All \\
\hline Improved Hb\% & None \\
\hline Passed round worm & \\
\hline Any sequel or adversity & \\
\hline
\end{tabular}




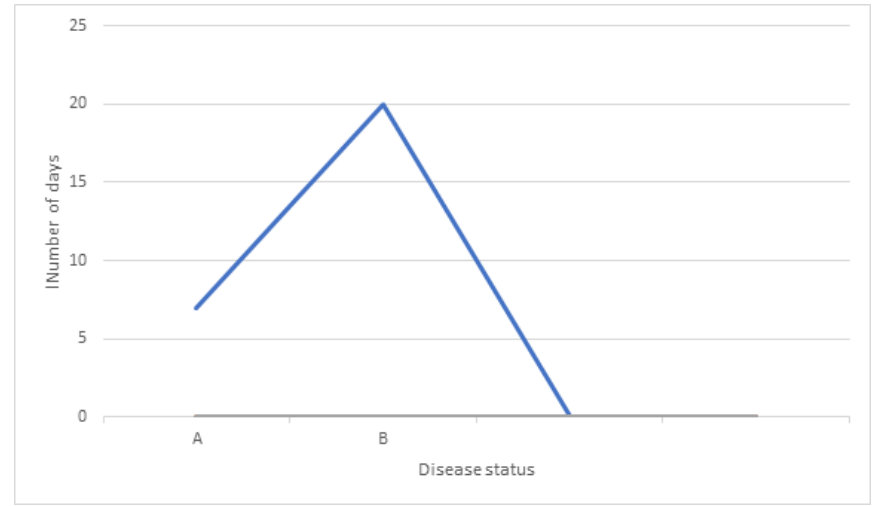

(Key word: A - Beginning of relief; B -complete subsidence of oedema)

Fig3. Showing pattern of relief of oedema during therapy.

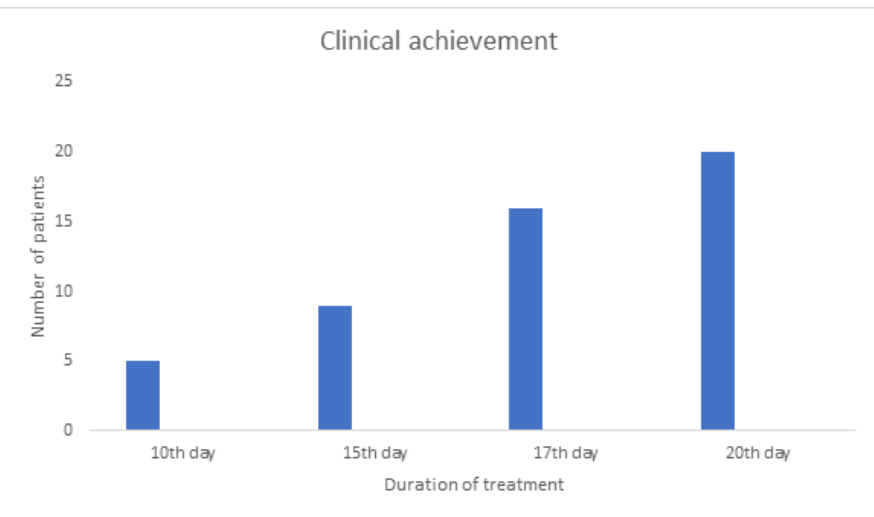

Fig4. showing clinical achievement

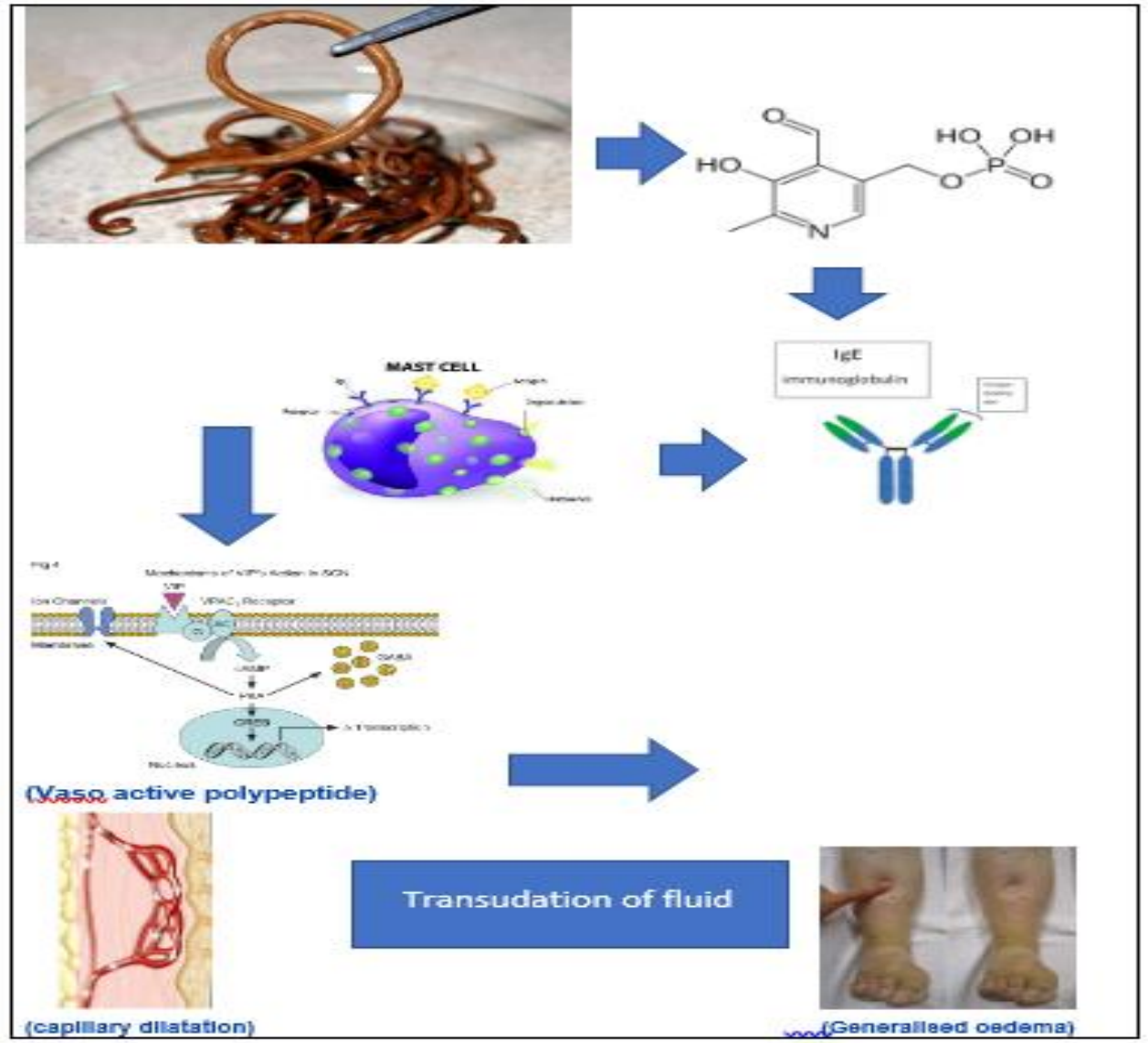

Fig5. Showing schematic presentation of pathogenesis of generalised pitting oedema. 


\section{OBSERVATION}

Selected patients were of age group 10-25 years (T-1) and out of them 13 were male and 07were female (Fig-1) and duration of illness varies from 5-9 days (Fig-2)

All patients have common presentation i.e.- Generalised pitting oedema, general debility, pain in abdomen and irregular bowel habit (T-2) and interrogation to rule out any associated hepatic or renal pathology were negative in all (T-3) duly confirmed by clinical examination (T-4) evaluation of haematological, diabetic hepatic and renal profile though all shows raised eosinophil count (T-5)

\section{RESUlt}

All patients had progressive decline in oedema and by $20^{\text {th }}$ day all had complete subsidence of oedema (Fig-3) and on deworming all passed plenty of round worm and achieved improved appetite.

No patient had any symptom withdrawal and any sequel.

\section{DisCUSSION}

Usually generalised pitting oedema is a presentation of either hepatic or renal pathology or malnutrition ${ }^{(12-13)}$,but generalised oedema due to non-nutritional Ascaris lumbricoides infestation is very uncommon but generalized oedema associated with Round worm symptomatology and passage of round worm on deworming with complete subsidence of oedema with deworming, anti-allergic and pyridoxin supplementation without any withdrawal and sequel or adversity (T-6)suggest -round worm toxin produced generalised pitting oedema , can be explained as -

Release of round worm toxin (Polypeptide) from the body of Ascaris lumbricoides which causes competitive inhibition of pyridoxal phosphatase enzyme which combine with IgE of mast cell which releases ${ }^{(14-15)}$

- vaso active polypeptide resulting in capillary dilation and exudation of subcutaneous fluid leading to generalized oedema.

- ATP-sensitive potassium channels can cause vasodilation due to hyperpolarization of vascular smooth muscle cells

\section{CONCLUSION}

In case of generalised oedema of acute onset with normal hepatic and renal profile, think of round worm as its causative parasite, investigate and treat accordingly.

\section{REFERENCES}

[1] Selzer, E. Ascariasis, Tropical infectious Disease, Principles. Pathogen and practice $1^{\text {st }}$ Edition, Guerrant, RL, Weller, PF (Eds), Philadelphia, Churchil Livingstone, 1999: 553

[2] Nasir Salam \& Saud Azam, Prevalence and distribution of soil-transmitted helminth infections in India BMC Public Health volume 17, Article number: 201 (2017)

[3] Prevalence of Soil transmitted helminths, W.H.O; $14^{\text {th }}$ March 2019

[4] Lobo DA, Velayudhan R, Chatterjee P, Kohli H, Hotez PJ. The neglected tropical diseases of India and South Asia: review of their prevalence, distribution, and control or elimination. PLoS Negl Trop Dis. 2011;5: e1222.

[5] Padmaja N, Swaroop PS, Nageswararao P. Prevalence of Intestinal Parasitic Infections among School Children in and around Amalapuram. J Pub Health Med Res. 2014;2(2):36-8.

[6] Panda S, Rao UD, Sankaram KR. Prevalence of intestinal parasitic infections among school children in rural area of Vizianagaram. IOSR J Pharm Biol Sci. 2012; 3:42-5.

[7] Ragunathan L, Kalivaradhan SK, Ramadass S, Nagaraj M, Ramesh K. Helminthic infections in school children in Puducherry, South India. J Microbiol Immunol Infect. 2010; 43:228-32.

[8] Golia S, Sangeetha K, Vasudha C. Prevalence of parasitic infections among primary school children in bangalore. Int J Basic Appl Med Sci. 2012; 4:12-8.

[9] Krishnan A, Sekar U, Sathanantham DK. Prevalence and Pattern of Helminthic Infection among Children in a Primary School of Rural Tamil Nadu. Acad Med J India. 2013; 1:40-2.

[10] Fernandez MC, Verghese S, Bhuvaneswari R, Elizabeth SJ, Mathew T, et al. A comparative study of the intestinal parasites prevalent among children living in rural and urban settings in and around Chennai. $\mathrm{J}$ Commun Dis. 2002; 34:35-9 
[11] Kathiryn P. Tryas, Sarah Pickle , Amber S. Tully, Edema: Diagnosis and Management Am Fam Physician. 2013 Jul 15;88(2):102-110.

[12] Pruna $A^{1}$. Generalized edema. Epidemiology, etiology, diagnosis, course and prognosis, treatmentRev Prat. 1991 Jan 21;41(3):259-70.

[13] Wang G, Cao WG, Zhao TL. Fluid management in extensive liposuction: A retrospective review of 83 consecutive patients. Medicine (Baltimore). 2018 Oct;97(41): e12655. [PMC free article] [PubMed]

[14] Sharma R, Sharma S. StatPearls [Internet]. StatPearls Publishing; Treasure Island (FL): Oct 27, 2018. Physiology, Blood Volume. [PubMed]

[15] Shankar, A. Edema of acute onset, a clinical manifestation of Ascaris infestation; Vol No Current Medical Practice

Citation: Dr. Avinash Shankar, et.al., (2019), "Oedema of Acute Onset, A Presentation of Round Worm Intoxication”. International Journal of Clinical Chemistry and Laboratory Medicine (IJCCLM), 5(3), pp.3036, DOI: http://dx.doi.org/10.20431/2455-7153.0503004.

Copyright: (C) 2019 Authors. This is an open-access article distributed under the terms of the Creative Commons Attribution License, which permits unrestricted use, distribution, and reproduction in any medium, provided the original author and source are credited. 